\title{
1,1-Dimethylhydrazine-Induced Diuresis
}

\author{
Mary L. Barth, Carol L. Geake, and Herbert H. Cornish \\ Department of Industrial Health, School of Public Health and \\ Institute of Industrial Health, University of Michigan \\ Ann Arbor, Michigan 48104
}

Received February 23, 1957

During earlier studies of the toxic effects of unsymmetrical dimethylhydrazine (UDMII), it was noted that $80 \mathrm{mg} / \mathrm{kg}$ of UDMII given intraperitoneally resulted in a 3-fold increase in urine excretion in the 6-hour period following injection (Cornish et al., 1966). Ten milligrams of UDMH injected intracerebrally also produced a marked diuresis.

The present study concerns the effects of antidiuretic hormone (ADH), nicotine tartrate, adrcnocorticotropic hormone (ACTH), adrenalectomy, pyridoxine (PY) and pyridoxal (PAL) on a UDMH-induced diuresis. The relationship of diuresis to electrolyte balance was studied by measuring concentrations of sodium, potassium, and calcium in urine, serum, and whole brain homogenate. Diuretic activity of related hydrazines was also determined.

\section{MATERIALS AND METHODS}

Male rats (225-300 g) of the Sprague-Dawley strain given a commercial feed $^{1}$ and water ad libitum were used in this study. Urine samples were collected from rats kept in individual metabolism cages designed to limit contamination of the sample with feces. Complete sample collection was achieved by abdominal pressure just prior to, and at the end of, each collection period except in the case of convulsing rats, when the final pressure treatment was omitted. Serum was obtained from blood samples taken from anesthetized rats by open chest heart puncture. The brains were removed from exsanguinated rats and homogenized in double-distilled water with an all-glass tissue homogenizer. Electrolyte concentrations were determined using a flame photometer. ${ }^{2}$ All compounds except vasopressin tannate and $\mathrm{ACTH}$ were diluted with $0.9 \% \mathrm{NaCl}$ prior to injection. Data are reported as the mean \pm one standard error.

\section{RESULTS}

\section{Route of Injection}

Four rats injected intracerebrally with $10 \mathrm{mg}$ of UDMH excreted an average of $14.0 \pm 5.4 \mathrm{ml}$ of urine (range: 3-26 ml) during the subsequent 6 hours (Cornish et al., 1966). This quantity of UDMH injected into groups of 6 rats by

${ }^{1}$ Rockland Rat and Mouse Chow, Teklad, Inc., Monmouth, Illinois.

? Coleman Model 21, Coleman Instruments Inc., Maywood, Illinois. 
other routes resulted in the following 6-hour average urine excretion volumes: intraperitoneal, $3.0 \pm 0.4 \mathrm{ml}$; intravenous, $3.0 \pm 0.2 \mathrm{ml}$; subcutaneous, $2.4 \pm 0.2$ $\mathrm{ml}$; and intramuscular, $2.8 \pm 0.4 \mathrm{ml}$. These volumes were not different from the average excretion of 28 untreated rats $(3.0 \pm 0.1 \mathrm{ml})$. All Sprague-Dawley rats used in subsequent studies were obtained from a different source, and it will be noted that the normal 6-hour urine volumes are considerably lower.

\section{Electrolyte Balance}

To study the relationship of onset of convulsions to possible alterations in electrolyte balance in UDMH-treated animals, urine, serum, and brain tissue samples were collected at 1 and 2 hours after treatment. Potassium and calcium levels were significantly decreased in both the 1-hour and 2-hour serum samples collected after the intraperitoneal injection of $80 \mathrm{mg} / \mathrm{kg}$ UDMH (Table 1).

TABLE 1

Average Serum Electrolyte Levels in Untreated and IDMH-Treated Ratg

\begin{tabular}{cccccc}
\hline $\begin{array}{c}\text { UDMH } \\
(\mathrm{mg} / \mathrm{kg})\end{array}$ & $\begin{array}{c}\text { Sacrifice } \\
\text { time (hours) }\end{array}$ & $\begin{array}{c}\text { Number } \\
\text { of rats }\end{array}$ & $\begin{array}{c}\mathrm{Na}^{+} \\
(\mathrm{meq} / \mathrm{l})\end{array}$ & $\begin{array}{c}\mathrm{K}^{+} \\
(\mathrm{meq} / \mathrm{l})\end{array}$ & $\begin{array}{c}\mathrm{Ca}^{++} \\
(\mathrm{meq} / \mathrm{l})\end{array}$ \\
\hline- & - & 14 & $14+1$ & $6.6 \pm 0.2$ & $6.8 \pm 0.1$ \\
80 & 1 & 7 & $143+1$ & $5.5 \pm 0.3^{a}$ & $6.3 \pm 0.1^{b}$ \\
80 & 2 & 13 & $145+1$ & $6.0 \pm 0.2^{a}$ & $6.5 \pm 0.1^{a}$ \\
100 & 2 & 12 & $141+1^{b}$ & $5.9 \pm 0.1^{b}$ & $6.3 \pm 0.1^{b}$
\end{tabular}

${ }^{a} P<0.05$.

${ }^{b} P<0.01$.

Sodium levels were not depressed until 2 hours after $100 \mathrm{mg} / \mathrm{kg}$ UDMH. Twenty-four hours after 80 and $100 \mathrm{mg} / \mathrm{kg} \mathrm{UDMH}$, average serum electrolyte levels were normal, but the range of calcium concentrations was much greater than for control rats.

The average urinary excretion of potassium and calcium during the first 2 hours after injection of $80 \mathrm{mg} / \mathrm{kg}$ UDMH was significantly less than that of normal rats (Table 2). Although the average sodium excretion appears depressed, the difference was not statistically significant.

TABIE 2

Excretion of $\mathrm{NA}^{+}, \mathrm{K}^{+}$, and $\mathrm{CA}^{++}$by Untreated and UDMH-InJected Ratsa

\begin{tabular}{cccc} 
Treatment & \multicolumn{3}{c}{ Amount excreted in 9 hours $(\mu \mathrm{eq})$} \\
\cline { 2 - 4 } group & $\mathrm{Na}^{+}$ & $\mathrm{K}^{+}$ & $\mathrm{Ca}^{++}$ \\
\hline Contreated & $231 \pm 35$ & $334 \pm 37$ & $43.5 \pm 8.4$ \\
CDMH, $80 \mathrm{mg} / \mathrm{kg}$ & $154 \pm 23$ & $213 \pm 18^{b}$ & $23.5 \pm 4.6^{c}$ \\
\hline
\end{tabular}

a Eleven rats per group.

${ }^{b} P<0.01$.

c $P<0.05$. 
Since the electrolyte levels in brain tissue might be most critical, whole brain homogenates were studied. The results are shown in Table 3. Calcium concentration was apparently depressed in the group of rats receiving $80 \mathrm{mg} / \mathrm{kg} \mathrm{UDMH}$ $(P<0.05)$. All other values for UDMH-treated rats were similar to values for controls.

TABLE 3

$\mathrm{NA}^{+}, \mathrm{K}^{+}$, and $\mathrm{CA}^{++}$Concentrations in Whole Brain Homogenate from Untreated AND UDMH-TrEATED RATS ${ }^{a}$

\begin{tabular}{|c|c|c|c|}
\hline \multirow[b]{2}{*}{ Treatment group } & \multicolumn{3}{|c|}{$\begin{array}{c}\text { Concentration } \\
\text { ( } \mu \text { eq per gram tissue, wet weight.) }\end{array}$} \\
\hline & $\mathrm{Na}^{+}$ & $\mathbf{K}^{+}$ & $\mathrm{Ca}^{++}$ \\
\hline Normals & $49.4 \pm 0.4$ & $90.2 \pm 1.1$ & $3.0 \pm 0.7$ \\
\hline $\mathrm{UDMH},^{b} 80 \mathrm{mg} / \mathrm{kg}$ & $50.9 \pm 0.6$ & $88.1 \pm 0.8$ & $1.7 \pm 0.2^{c}$ \\
\hline $\mathrm{UDMH}^{b}{ }^{b} 100 \mathrm{mg} / \mathrm{kg}$ & $50.5 \pm 0.5$ & $90.8 \pm 0.7$ & $3.1 \pm 0.4$ \\
\hline
\end{tabular}

a Twelve rats per group.

${ }^{b}$ Animals were sacrificed at 2 hours after injection.

$\circ P<0.05$.

\section{Antidiuretic Hormone}

Since $10 \mathrm{mg}$ of UDMH per rat injected intracerebrally will produce diuresis in rats whereas a similar dose injected by other routes has no effect, it appeared necessary to include in this investigation a study of mechanisms by which diuresis may be centrally mediated. Rats were given simultaneous injections of $80 \mathrm{mg} / \mathrm{kg}$ UDMH intraperitoneally and 500 milliunits $(\mathrm{mU})$ of vasopressin

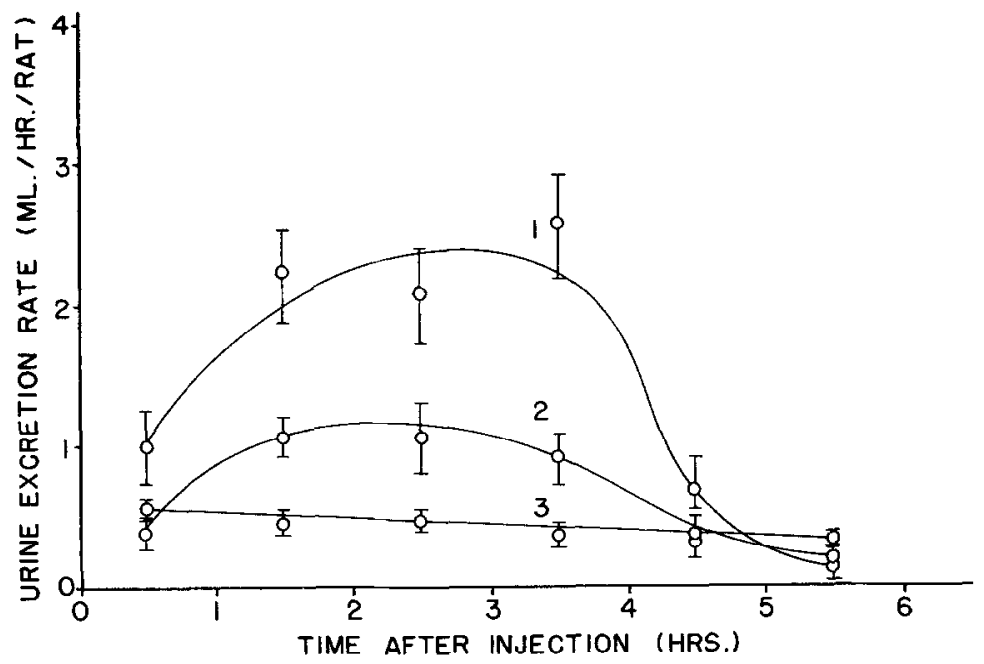

FIG. 1. Effect of antidiuretic hormone on UDMH-induced diuresis. Curve $1,80 \mathrm{mg} / \mathrm{kg}$ UDMH (ip); curve $2,80 \mathrm{mg} / \mathrm{kg}$ UDMH (ip) plus 500 milliunits of $\mathrm{ADH}$ in peanut oil (ip) simultaneously; curve 3 , untreated rats. 
tannate $(\mathrm{ADH})$ in peanut oil intramuscularly. The urine excretory rate of UDMH-treated rats approximated $2.0 \mathrm{ml}$ per hour compared with a rate of less than $0.5 \mathrm{ml}$ per hour for control rats (Fig. 1). ADH decreased the urinary excretion rate by approximately $50 \%$ in UDMH treated rats; however, this is still considerably above control levels. In both groups of UDMH-treated rats diuresis lasted about 4 hours. This was followed by a period of water retention.

\section{Nicotine Tartrate}

Thirty-two rats, injected with $80 \mathrm{mg} / \mathrm{kg}$ of UDMH and given $4.5 \mathrm{mg} / \mathrm{kg}$ of nicotine tartrate subcutaneously 1 hour later, had urine excretion rates approximately one-half that of a comparable group of rats given UDMH only (Fig. 2A). UDMH-treated rats given nicotine tartrate had more convulsions than rats given UDMH only. In addition, 19 of 32 rats receiving both nicotine tartrate and UDMH died, compared to 4 of 38 rats receiving UDMH only. A similar effect of nicotine tartrate in reducing urine excretion in water-loaded rats given $7 \mathrm{ml}$ of water by gavage at $0,1,2$, and 3 hours is shown in Fig. $2 \mathrm{~B}$. In both studies the effect of nicotine tartrate is apparent over a relatively short period of 1-2 hours.

\section{Effect of Adrenalectomy on UDMH-Induced Diuresis}

Twelve rats were adrenalectomized under ether anesthesia and allowed to recover for 4 days. Following surgery, they were given $1 \% \mathrm{NaCl}$ as drinking water. Six of the adrenalectomized rats were injected intraperitoneally with $80 \mathrm{mg} / \mathrm{kg}$ of UDMH and the remaining 6 rats with the same volume of $0.9 \%$ $\mathrm{NaCl}$. On the following day, 4 of the 6 control rats from the previous day were given $80 \mathrm{mg} / \mathrm{kg}$ of UDMH. Urine volumes were measured at half-hour intervals.

This dose of UDMH proved to be lethal to adrenalectomized rats and they began to die after $3 \frac{1}{2}$ hours. Three hours after UDMH injection, adrenalectomized rats displayed no diuresis, urine volume averaging $1.4 \pm 0.3 \mathrm{ml}$ compared with $1.7 \pm 0.7 \mathrm{ml}$ for adrenalectomized controls. Eighteen intact rats given $80 \mathrm{mg} / \mathrm{kg}$ of UDMH had excreted $5.6 \pm 0.5 \mathrm{ml}$ of urine by this time.

\section{The Effect of ACTH on UDMH-Induced Diuresis}

The effect of intramuscular ACTH on diuresis induced by $80 \mathrm{mg} / \mathrm{kg}$ of UDMH given intraperitoneally was studied. Four groups of 6 rats each were treated as follows: group I received UDMH only; group II received UDMH and 5 units $(\mathrm{U})$ of ACTH simultaneously; group III received UDMH and $5 \mathrm{U}$ of ACTH simultaneously plus $5 \mathrm{U}$ of ACTH 1 hour later; and group IV received two $5 \mathrm{U}$ doses of ACTH 1 hour apart. Group V comprised 18 normal controls. Hourly urine volumes were taken.

The average 6-hour urine excretions of groups I, II, III, IV, and V were $7.3 \pm$ $0.4,7.8 \pm 0.7,3.8 \pm 0.7,3.4 \pm 0.4$, and $1.8 \pm 0.3 \mathrm{ml}$, respectively. Thus five units of ACTH given simultaneously with UDMH had no effect on the diuresis. Two $5 \mathrm{U}$ doses of ACTH administered 1 hour apart reduced urine excretion of 

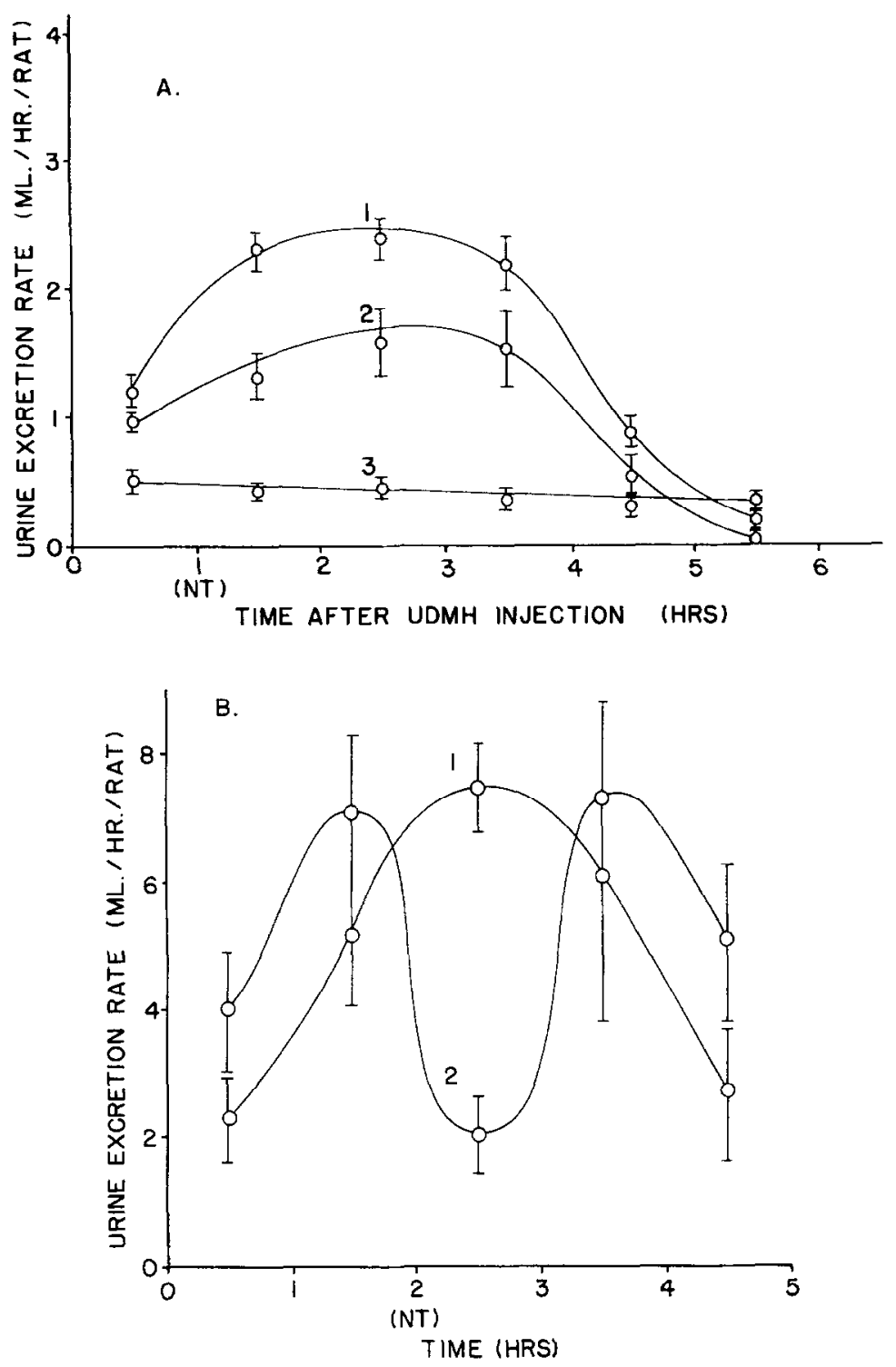

Fig. 2. Effect of nicotine tartrate (NT) on diuresis. (A) curve $1,80 \mathrm{mg} / \mathrm{kg}$ UDMH (ip); curve $2,80 \mathrm{mg} / \mathrm{kg}$ UDMH (ip) plus $4.5 \mathrm{mg} / \mathrm{kg}$ NT subcutaneously 1 hour after UDMH; curve 3, untreated rats. (B) Curve 1, water-loaded rats, $7 \mathrm{ml}$ water by gavage at $0,1,2$, and 3 hours; curve 2 , similar water load plus $5 \mathrm{mg} / \mathrm{kg} \mathrm{NT}$ at 2 hours.

UDMH-treated rats to that of the corresponding control group IV. 'Ihis ACTH control group, however, showed some diuresis when compared to untreated animals $(P<0.01)$. It was noted that 12 rats which received ACTH with UDMH had a total of 50 convulsions compared with 3 apparent convulsions for 6 rats receiving only UDMH. Four of the ACTH-UDMH treated rats died whereas all of the UDMH controls survived. 


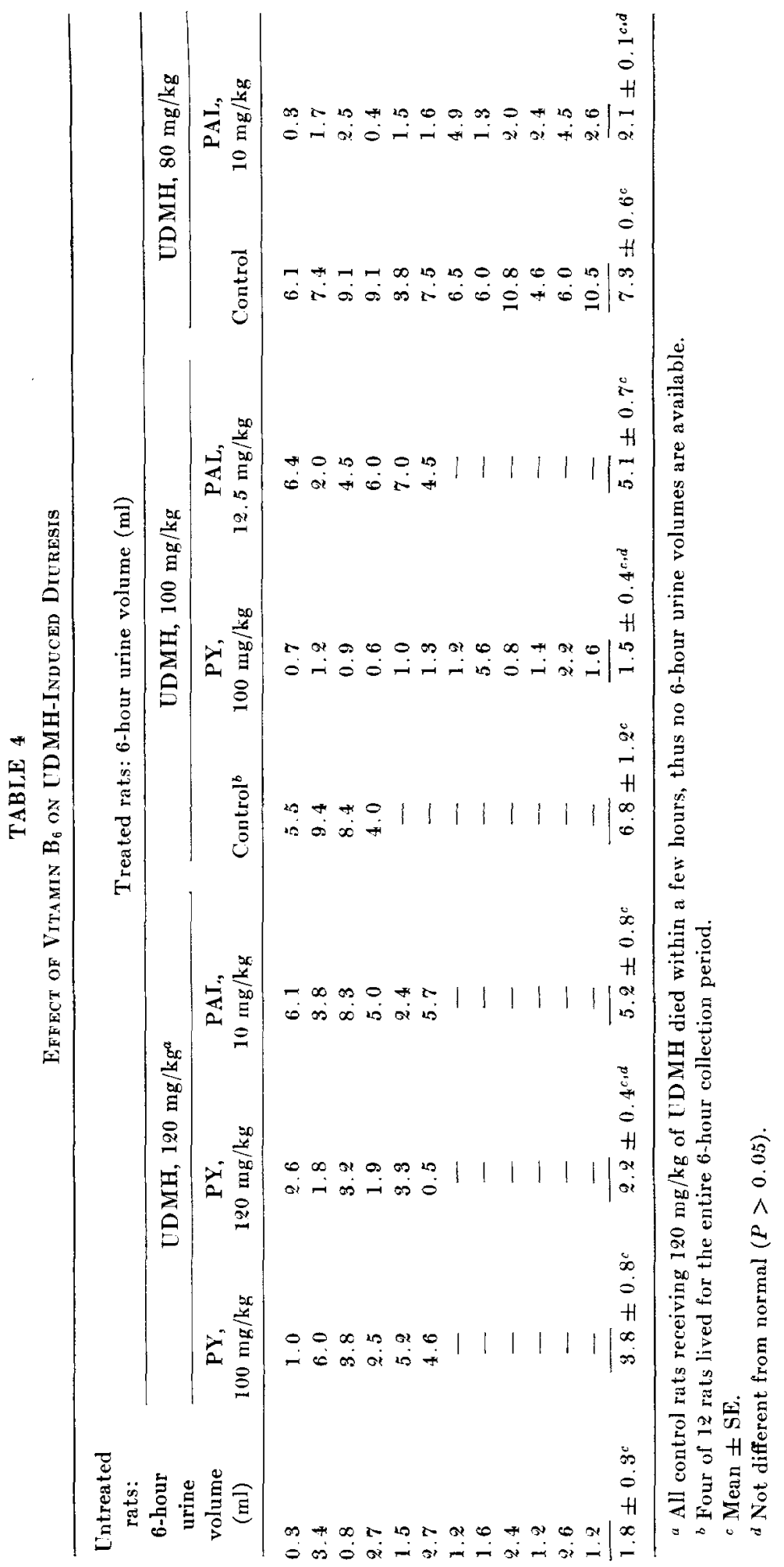




\section{Effect of Vitamin $B_{6}$ on UDMH-Induced Diuresis}

The effect of various $B_{6}$ vitamers on UDMH-induced diuresis is shown in Table 4 . The average 6 hour urine output for 12 normal rats was $1.8 \_0.3 \mathrm{ml}$. When rats were injected with $120 \mathrm{mg} / \mathrm{kg}$ of UDMH, there were not sufficient survivors to furnish a control group. However, treatment with $100 \mathrm{mg} / \mathrm{kg}$ of PY not only allowed animals to survive, but their average urine output was considerably below that of animals receiving 80 or $100 \mathrm{mg} / \mathrm{kg}$ of UDMH. PY at $120 \mathrm{mg} / \mathrm{kg}$ returned urine output to normal ranges in all UDMH-injected rats. PAL at an intraperitoneal dosage of $10 \mathrm{mg} / \mathrm{kg}$ was not effective in preventing diuresis in all animals receiving a lethal dose $(120 \mathrm{mg} / \mathrm{kg})$ of UDMH although these animals did survive. When $100 \mathrm{mg} / \mathrm{kg}$ (an approximate $\mathrm{LD}_{50}$ ) of UDMH was given, $100 \mathrm{mg} / \mathrm{kg}$ of PY prevented diuresis in 11 of 12 rats. PAL at a dosage of $12.5 \mathrm{mg} / \mathrm{kg}$ prevented mortality but did not prevent diuresis. At a dosage of $80 \mathrm{mg} / \mathrm{kg}$ of UDMH, animals were still markedly diuretic; however, this effect was reversed by $10 \mathrm{mg} / \mathrm{kg}$ PAL in 10 of 12 rats.

Diuretic Effect of Hydrazine, Monomethylhydrazine, and sym-Dimethylhydrazine

Hydrazine ( $50 \mathrm{mg} / \mathrm{kg}$, ip) and monomethylhydrazine $(20 \mathrm{mg} / \mathrm{kg}$, ip) produced diuresis in rats, but sym-dimethylhydrazine, even at a dose of 200 $\mathrm{mg} / \mathrm{kg}$ did not (Table 5 ).

TABLE 5

Druretic Effect of Various Hydrazines

\begin{tabular}{|c|c|c|}
\hline \multicolumn{3}{|c|}{ Urine excreted during the 6 -hour postinjection period (ml) } \\
\hline $\begin{array}{l}\text { Hydrazine, } \\
50 \mathrm{mg} / \mathrm{kg}\end{array}$ & $\begin{array}{l}\text { Monomethyl. } \\
\text { hydrazine, } \\
20 \mathrm{mg} / \mathrm{kg}\end{array}$ & $\begin{array}{l}\text { sym-Dimethyl- } \\
\text { hydrazine, } \\
200 \mathrm{mg} / \mathrm{kg}\end{array}$ \\
\hline 7.6 & 6.2 & 1.8 \\
\hline 7.4 & 5.0 & 0.6 \\
\hline 7.4 & 9.4 & 0.4 \\
\hline 4.1 & 4.7 & 2.6 \\
\hline 6.0 & 5.3 & 0.5 \\
\hline- & 5.7 & 0.4 \\
\hline$\overline{6.5} \pm 0.7^{a \cdot b}$ & $\overline{6.0} \pm 0.7^{a, b}$ & $\overline{1.0} \pm 0.4^{a}$ \\
\hline
\end{tabular}

a Mean \pm one standard error.

${ }^{b}$ Significantly different from the average of 52 normal rats $(1.7 \pm 0.1 \mathrm{ml})$ with $P<0.001$.

\section{DISCUSSION}

Although slight, but significant, depressions of serum potassium, calcium, and in one group, sodium levels occurred in UDMH-treated rats, it is doubtful that such alterations reflect a major disturbance of electrolyte balance. Although the 
average brain calcium level in rats treated with $80 \mathrm{mg} / \mathrm{kg}$ of UDMH appeared slightly depressed, this was not confirmed in a subsequent series of animals receiving a $100 \mathrm{mg} / \mathrm{kg}$ dose. Apparently a major electrolyte imbalance does not precede onset of convulsions in UDMH-treated rats. In addition the urine electrolyte data show that UDMH does not produce a salt diuresisthus other mechanisms must be considered.

ADH seems to be functional in UDMH-treated rats since it depressed diuresis for a number of hours. The antidiuretic effect of nicotine as a demonstration of a functioning neurohypophyseal system has been discussed by Burn (1951) and reviewed by Gaunt et al. (1963). In the present study it appeared that the dose level of nicotine tartrate was rather critical; $4.5 \mathrm{mg} / \mathrm{kg}$ significantly reduced diuresis in UDMH-treated rats for a short period of time, whereas smaller doses were ineffective. These data suggest that stimulation of the neurohypophyseal system of UDMH treated rats will release functional ADH. Thus, although the intracerebral results and the water diuresis are suggestive of ADH deficiency, the present studies do not reveal a specific mechanism for ADH involvement in UDMH induced diuresis.

As might be anticipated, adrenalectomized animals were not able to withstand usually sublethal doses of UDMH. Even so, the diuresis apparent at 3 nours after dosage in intact animals was not seen in adrenalectomized rats. Interestingly, in control rats, two 5-unit doses of ACTH also prevented the marked UDMH diuresis.

Since adrenalectomized animals are unable to excrete a water load, even when corrected by increased salt intake (Tepperman, 1962), any action of UDMH to alter water distribution in adrenalectomized animals might not necessarily result in diuresis. Similarly, ACTH-stimulated release of corticosterone in rats may produce an antidiuretic action by influencing water distribution in tissues (Tepperman, 1962). Such action may account for the lack of diuresis in UDMH-injected animals treated with ACTH.

Since vitamin $\mathrm{B}_{6}$ has been shown by a number of investigators (Back et al., 1963; Dubnick et al., 1960) to be effective in preventing the convulsive effects of UDMH, the ability of this vitamin to prevent diuresis was also investigated. Appropriate doses of pyridoxine prevented fatalities and returned urine volumes to normal in UDMH-treated animals. Due to its toxicity, doses of pyridoxal comparable to the pyridoxine dose could not be utilized. However, diuresis produced by $80 \mathrm{mg} / \mathrm{kg}$ of UDMH could be readily reversed by $10 \mathrm{mg} / \mathrm{kg}$ of PAL (Table 4 ). The ability of $\mathrm{B}_{6}$ to prevent diuresis in UDMH-treated animals suggests that the diuresis may reflect a physiological imbalance brought on by the effect of UDMH on $\mathrm{B}_{6}$-dependent biochemical reactions, or that $\mathrm{B}_{6}$ may play a role in water reabsorption independent of other mechanisms.

Hydrazine, monomethylhydrazine, and UDMH produced diuresis in rats (Table 5). High doses of sym-dimethylhydrazine produced no such response. Apparently a free amino group is a prerequisite for diuretic activity in this series of hydrazines. It is of interest that the three hydrazines which are capable of producing diuresis are also able to react chemically with the aldehyde forms of vitamin $\mathbf{B}_{6}$. Sym-Dimethylhydrazine does not undergo this reaction. 


\section{SUMMARY}

Intraperitoneal injections of $80-100 \mathrm{mg} / \mathrm{kg}$ of UDMH produced a marked diuresis in rats. Injections of $10 \mathrm{mg}$ per rat resulted in diuresis only when given by the intracerebral route. Although there are significant alterations in the excretory pattern of electrolytes, serum and brain electrolyte levels did not appear to be appreciably altered at the time corresponding to onset of convulsions. Injected $A D H$ is functional in UDMH-treated rats arid the action of nicotine tartrate suggests the presence of a functioning neurohypophyseal system. The diuresis can be reversed by appropriate doses of vitamin $B_{6}$. Hydrazine, monomethylhydrazine, and UDMH produce diuresis in rats. Symmetrical dimethylhydrazine, even at high doses does not; thus a free amino group appears to be necessary for diuretic activity in this series of hydrazines.

\section{ACKNOWLEDGMENTS}

This work was sponsored by the Commission on Environmental Hygiene, of the Armed Forces Epidemiological Board, and was supported, in part, by the Medical Research and Development Command, Office of the Surgeon General, Department of the Army of the United States.

We wish to thank Dr. Leonard T. Blouin, Parke, Davis and Company, for valuable suggestions in the preparation of the manuscript.

In conducting this study the investigators adhered to the "Guide for Laboratory Animal Facilities and Care," as promulgated by the National Academy of Sciences-National Research Council.

\section{RFFF.RENCES}

Back, K. C., Pinkerton, M. T., and Thomas, A. A. (1963). Therapy of acute UDMH intoxication. Aerospace Med. 34, 1001-1004.

Burn, J. H. (1951). Antidiuretic effect of nicotine and its implications. Brit. Med. J. II, $199-210$.

Cornish, H. H., Geake, C. L., and Barth, M. L. (1966). Biological action of 1,1dimethylhydrazine. Biochem. Pharmacol. 14, 1901-1904.

Dubnick, B., Leeson, G. A., and Scott, C. C. (1960). Effect of forms of vitamin $B_{\theta}$ on acute toxicity of hydrazines. Toxicol. Appl. Pharmacol. 2, 403-409.

Gaunt, R., Chart, J. J., and Renzi, A. A. (1963). Interactions of drugs with endocrines. Ann. Rev. Pharmacol. 3, 117.

Tepperman, J. (1962). "Metabolic and Endocrine Physiology," p. 107. Year Book Medical Publishers, Chicago, Illinois. 